\title{
Effects of Ni-P Substrate Structure and Pd/Au Film Thicknesses on the Wire Bonding Strength of Electroless $\mathrm{Au} / \mathrm{Pd} / \mathrm{Ni}-\mathrm{P}$ Films
}

\author{
Yuichi Saito***, Hajime Terashima*, Takeshi Muramatsu***, Hideto Watanabe***, \\ Ichiro Koiwa ${ }^{* * * *}$ and Hideo Honma**** \\ * Graduate School of Engineering, Kanto Gakuin University, Yokohama 236-8501, Japan \\ ** Kanto Gakuin University Surface Engineering Research Institute, Yokosuka 239-0806, Japan \\ *** Chemicals Division, Kojima Chemicals Co., Ltd., Sayama 350-1335, Japan \\ **** Department of Applied Material and Life Science, Faculty of Engineering, Kanto Gakuin University, Yokohama 236-8501, Japan
}

(Received March 29, 2007; accepted October 22, 2007)

\begin{abstract}
The local corrosion of nickel can occur during the gold plating in $\mathrm{Au} / \mathrm{Ni}$ fabrication processes. The wire bonding strength decreases as the nickel is diffused to the gold surface by the heat treatment. Accordingly, palladium plating is generally applied as an interlayer between the nickel plating and the gold plating to avoid the local corrosion of nickel. However the influence of the nickel layer structure and the noble metal film thickness on the wire bonding strength has not been investigated in detail. In this study, we investigated how the structure of the deposited nickel and the thickness of the noble metal film influenced the wire bonding properties. The bonding strength of nickel was higher with a layered structure than with a columnar structure when the gold and palladium films were $0.05 \mu \mathrm{m}$ thick.
\end{abstract}

Keywords: Au/Pd/Ni-P, Ni-P Structure, Wire Bonding, Diffusion, Electroless Plating

\section{Introduction}

On a printed circuit board, soldering and wire bonding are the main methods used to mount the electronic devices and parts. Since it is usually difficult to connect gold wire directly on a copper pad, electroless $\mathrm{Ni}-\mathrm{P}$ and gold films are plated on the copper pads first. The use of electroless $\mathrm{Ni}-\mathrm{P}$ and gold plating gives the designer the ability to downsize the boards by eliminating the conductive lead for electroplating. Gold plating is necessary for wire bonding and suppressing oxidation of the $\mathrm{Ni}-\mathrm{P}$ surface and Ni-P plating is necessary to suppress the diffusion of gold and copper. During soldering, the plated gold films diffuse into the solder and at works to suppress the oxidation of the Ni-P films. However, for wire bonding, a gold wire is connected to the plated gold film surface. For the gold-gold connection, the surface condition of the plated gold film is quite important to obtain proper wire bonding strength.[1] Soldering and wire bonding are both generally applied on one printed circuit board. The solder is generally heat treated before wire bonding. Generated heat during the soldering process causes the nickel to dif- fuse into the gold films and nickel can reach the surface of the gold layer. The existence of nickel on the gold surface deteriorates wire bonding strength.[2-4] Accordingly, many workers have investigated electroless palladium plating as the interlayer between $\mathrm{Ni}-\mathrm{P}$ and $\mathrm{Au}$ to prevent Ni diffusion to Au surface.[5-9]

In this paper, we have investigated the effect of the $\mathrm{Ni}-\mathrm{P}$ structure on wire bonding strength for a $\mathrm{Au} / \mathrm{Pd} / \mathrm{Ni}-$ P system.

\section{Experimental}

\subsection{Plating conditions and observation of films}

A $0.6 \mathrm{~mm}$ thick ball grid array (BGA) substrate was used for wire bonding tests. The BGA boards had copper pads whose diameter and pitch were $0.65 \mathrm{~mm}$ and $1.27 \mathrm{~mm}$, respectively. The substrates were pretreated by both acid degreasing at $40^{\circ} \mathrm{C}$ for 4 minutes, and activation by sulfuric acid at room temperature for 1 minute. Then, the substrates were immersed in the activating solution which contained $\mathrm{PdCl}_{2}$ of $0.1 \mathrm{~g} / \mathrm{dm}^{3}$. After removal from the rinse, the substrate was dipped into the electro- 
(a)

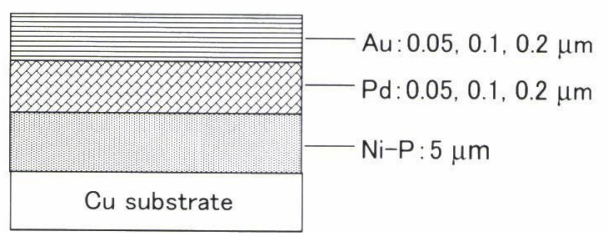

(b)

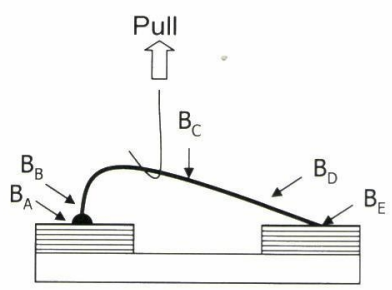

Fig. 1. The cross-sectional substrate images: (a) the cross-sectional substrate image with plating film thicknesses, and (b) the measurement image of failure mode on wire pull test. The failure mode was $B_{C}>B_{B}, B_{D}>B_{E}, B_{A}$.

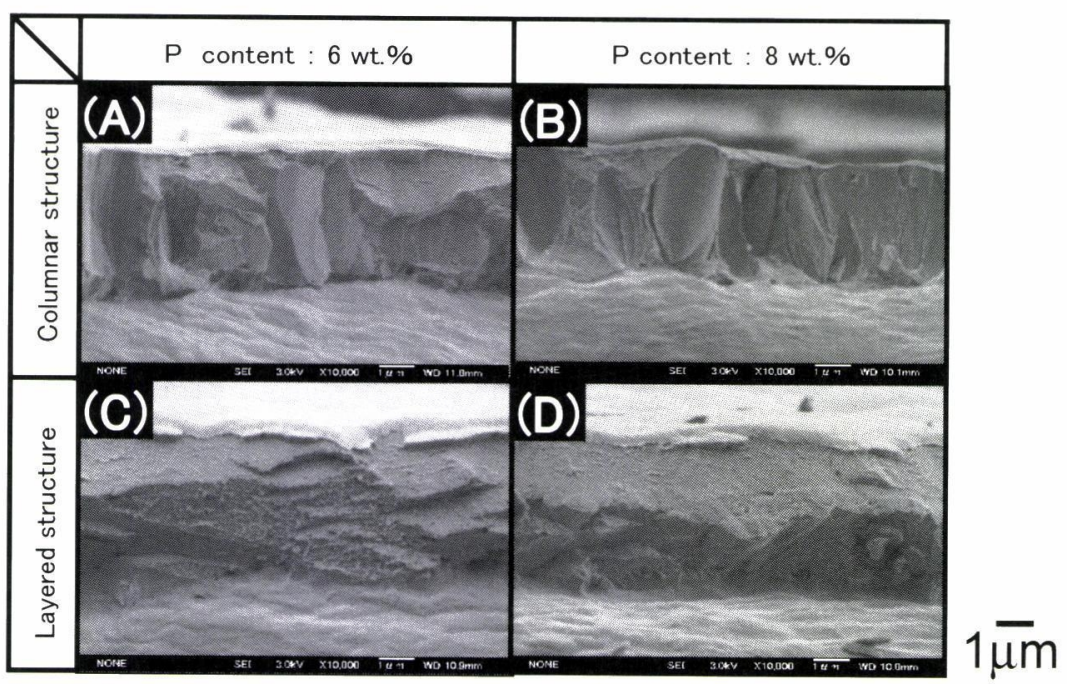

Fig. 2. Cross-sectional SEM micrographs of the 4 types of electroless Ni-P films.

less Ni-P plating solution. Figure 1(a) shows the thicknesses of $\mathrm{Au} / \mathrm{Pd} / \mathrm{Ni}-\mathrm{P}$ substrate. In this investigation, electroless $\mathrm{Ni}-\mathrm{P}$ films were plated at $5 \mu \mathrm{m}$ on the treated copper pads. Electroless palladium was plated on the $\mathrm{Ni}-\mathrm{P}$ films, at various thicknesses, from $0.05 \mu \mathrm{m}$ to $0.2 \mu \mathrm{m}$. The electroless palladium plating bath contained formic acid as a reducing agent. After removal from the rinse, the substrate was dipped into the immersion gold plating solution. Immersion gold $(0.05 \mu \mathrm{m})$ was plated on the Pd films. Furthermore, to evaluate the effect of $\mathrm{Au}$ thickness, electroless gold films were plated to produce the $0.1 \mu \mathrm{m}$ and $0.2 \mu \mathrm{m}$ samples.

A surface and cross-section of the films were observed by scanning electron microscopy (SEM; JEOL, JSM$7000 \mathrm{~F})$. The phosphorus contents of the Ni-P films were determined by electron probe micro analyzer (EPMA; JEOL, JXA-8900R). Surface and depth profiles of the films were analyzed by auger electron spectroscopy (AES; JEOL, JAMP-7100).

\subsection{Wire bonding}

Figure 1(b) shows the measurement image of failure mode. Gold wire of $25 \mu \mathrm{m}$ diameter was bonded to the BGA board with load of $70 \mathrm{gf}$ for $110 \mathrm{~ms}$ at $160^{\circ} \mathrm{C}$. A wire bonding property was evaluated by a wire pull tester at pull speed of $12.5 \mathrm{~mm}$ per minute. The wire bonding properties were evaluated using 20 samples in one condition. A failure mode was divided as follows by different fracture interface $\mathrm{B}_{\mathrm{A}}$ : Au film/Ball, $\mathrm{B}_{\mathrm{B}}$ : Ball/Wire, $\mathrm{B}_{\mathrm{C}}$ : Wire fracture, $B_{D}$ : Wire/Au film (Wire residue), $B_{E}$ : Wire/ $\mathrm{Au}$ film (without wire residue). The failure mode was $B_{C}>B_{B}, B_{D}>B_{E}, B_{A}$. The variation of failure mode was evaluated.

\section{Results and Discussion}

\subsection{Characteristics of electroless Ni-P films}

Characteristics of four types of Ni-P films are summarized in Table 1. Figure 2 shows cross-sectional SEM images of the four electroless $\mathrm{Ni}-\mathrm{P}$ films. As shown in Table 1, Ni-P films produced from baths A and B using a mixture of complexing agents, succinic acid and malic acid, showed columnar structure. On the other hand, $\mathrm{Ni}-\mathrm{P}$ films produced from baths $\mathrm{C}$ and $\mathrm{D}$ using a differ- 
ent mixture of complexing agents, lactic acid and malic acid, showed layered structure. Phosphorus contents of these films were $6.2,7.9,6.1$, and $8.2 \mathrm{wt} . \%$, respectively, as measured by EPMA. The Ni-P films from baths $\mathrm{A}$ and $\mathrm{C}$ showed almost the same phosphorus content but showed different structures. The Ni-P films from baths B and $\mathrm{D}$ also showed almost the same phosphorus contents but shows different structure. In general, the phosphorus content of an electroless Ni-P film can be controlled, from 3 wt. $\%$ to 14 wt. $\%$. In this investigation, the phosphorus content the films is not wide: all films are medium phosphorus content. The differences of the phosphorus contents are not large but the cross-sectional structures are quite different. These results suggested that these structure differences are caused by differences in the complexing agents, and are not caused by phosphorus content.

\subsection{Effect of Pd thickness on wire bonding strength}

Figures 3 and 4 demonstrate the effect of Pd thickness on wire bonding properties, before heat treatment and after heat treatment, respectively. In this study we investigated, four types of $5 \mu \mathrm{m}$ electroless Ni-P films with electroless palladium films, plated at three thickness, $0.05 \mu \mathrm{m}, 0.1 \mu \mathrm{m}$, and $0.2 \mu \mathrm{m}$, respectively, as shown in

Table 1. Nickel structure and phosphorus content of various $\mathrm{Ni}-\mathrm{P}$ substrates.

\begin{tabular}{l|c|c|c|c}
\hline Plating bath & A & B & C & D \\
\hline Ni structure & Columnar & Columnar & Layer & Layer \\
\hline $\begin{array}{l}\text { Complexing } \\
\text { agents }\end{array}$ & \multicolumn{2}{|c|}{$\begin{array}{r}\text { Succinic Acid } \\
\text { Malic Acid }\end{array}$} & \multicolumn{2}{|c|}{$\begin{array}{l}\text { Lactic Acid } \\
\text { Malic Acid }\end{array}$} \\
\hline $\begin{array}{l}\text { P content } \\
\text { [wt.\%] }\end{array}$ & 6 & 8 & 6 & 8 \\
\hline
\end{tabular}

(a)

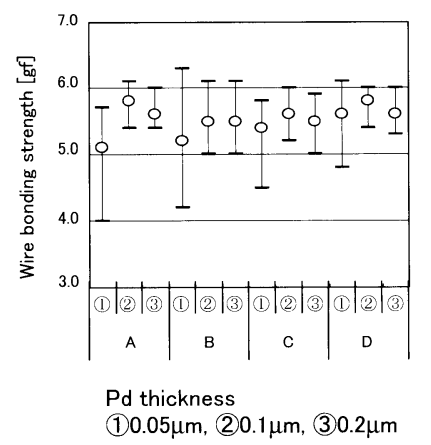

Table 1 and Fig. 3. All samples had a $0.05 \mu \mathrm{m}$ Au film over the Pd film.

Figure 3 shows the results of wire bonding strength before heat treatment. In this paper, four different types of Ni-P films, designated as A, B, C, and D, were investigated. There were three different thicknesses of Pd films, $0.05 \mu \mathrm{m}, 0.1 \mu \mathrm{m}$, and $0.2 \mu \mathrm{m}$, plated on each type of $\mathrm{Ni}-\mathrm{P}$ film. As shown in Fig. 3, before the heat treatment, all $\mathrm{Ni}-\mathrm{P}$ films with different Pd thicknesses showed the wire bonding strengths above $5.5 \mathrm{gf}$.

Figure 4 shows the wire bonding strength results after heat treatment at $200^{\circ} \mathrm{C}$ for 1 hour as the same manner as shown in Fig. 3. Nine samples showed wire bonding strength ranging from $5.5 \mathrm{gf}$ to $6.0 \mathrm{gf}$. Only three samples showed bonding strength lower than 5.5 gf. The three lowest values obtained were from samples with $0.05 \mu \mathrm{m}$ Pd thicknesses. Only Ni-P film D with $0.05 \mu \mathrm{m} \mathrm{Pd}$,

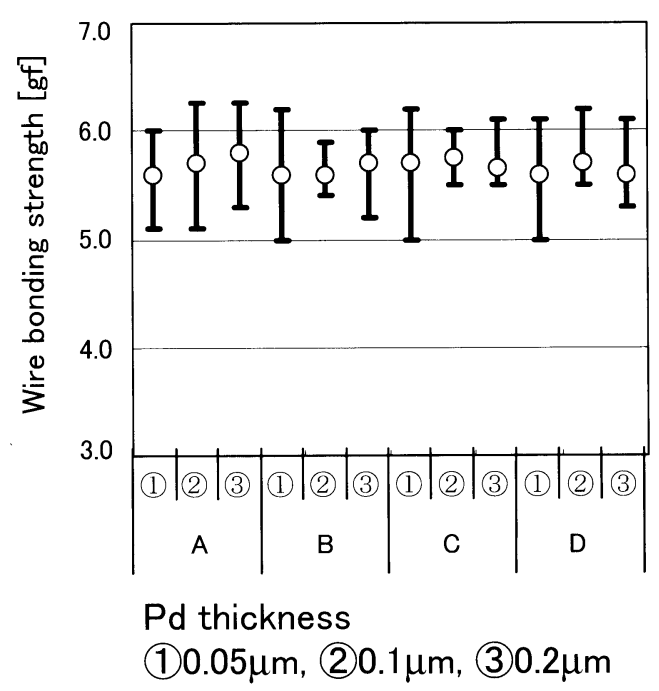

Fig. 3. Effect of palladium thickness on wire bonding strength for the $\mathrm{Au} / \mathrm{Pd} / \mathrm{Ni}-\mathrm{P}$ system, before heat treatment. $\mathrm{Au}$ thickness is $0.05 \mu \mathrm{m}$ to all samples.

(b)

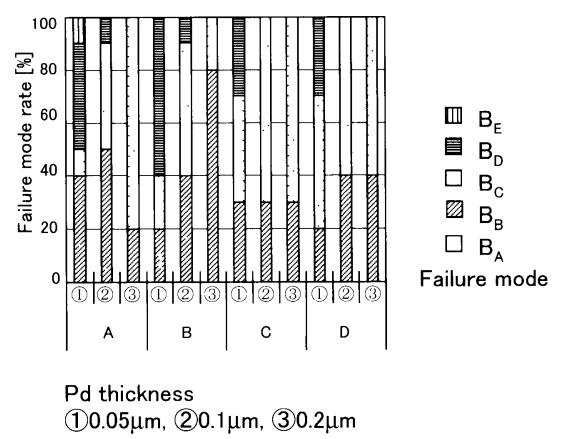

Fig. 4. Effect of palladium thickness on wire bonding properties for the $\mathrm{Au} / \mathrm{Pd} / \mathrm{Ni}-\mathrm{P}$ system, after heat treatment: (a) wire bonding strength, and (b) failure mode. Au thickness is $0.05 \mu \mathrm{m}$ to all samples. 
(a)

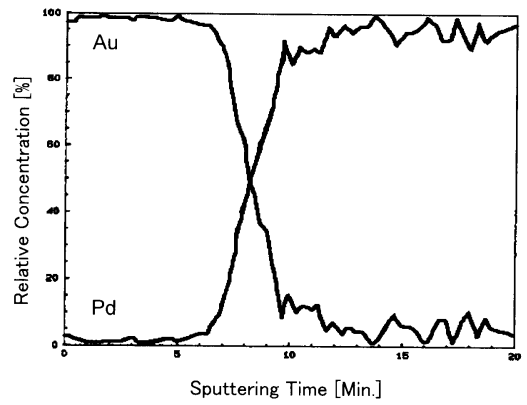

(b)

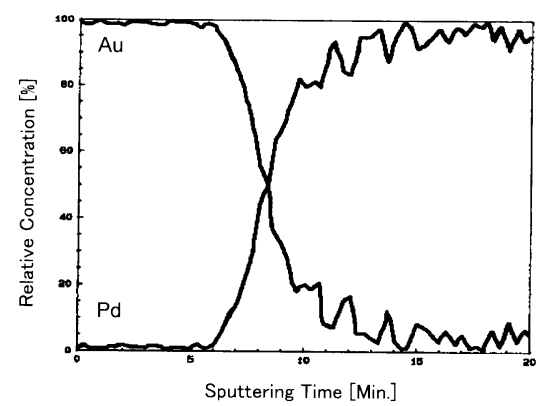

Fig. 5. AES measurements for the Au/Pd/Ni-P system, before heat treatment. The Ni-P A samples with (a) $0.05 \mu \mathrm{m}$ and (b) $0.2 \mu \mathrm{m}$ thickness Pd films are samples $\mathrm{A} 1$ and $\mathrm{A} 3$, as shown in Fig. 3.

(a)

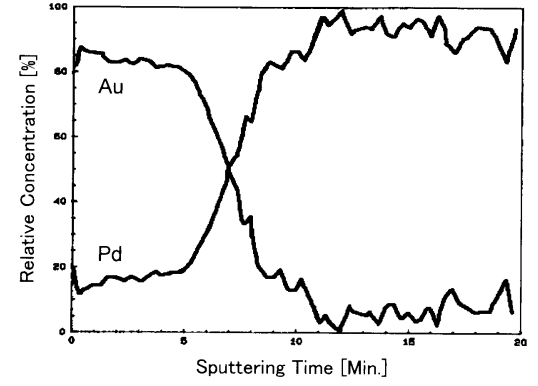

(b)

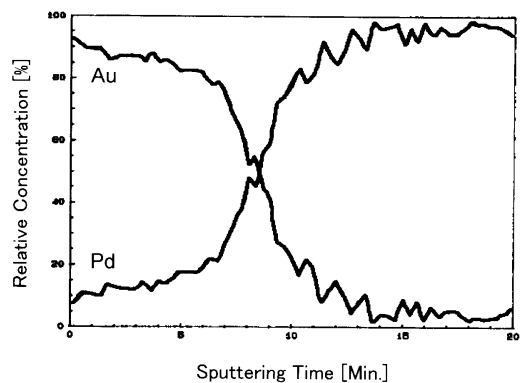

Fig. 6. AES measurements for the $\mathrm{Au} / \mathrm{Pd} / \mathrm{Ni}-\mathrm{P}$ system, after heat treatment. The Ni-P A sample with (a) $0.05 \mu \mathrm{m}$ and (b) $0.2 \mu \mathrm{m}$ thickness Pd films are samples A1 and A3, as shown in Fig. 4.

showed a wire strength value higher than 5.5 gf. However, for all Ni-P films, the variations of wire bonding strengths for the $0.05 \mu \mathrm{m}$ Pd thickness samples were larger than those for the thicker Pd films. Ni-P A films with a $0.05 \mu \mathrm{m}$ Pd thickness, showed lower of wire bonding strength than the other three Ni-P films with $0.05 \mu \mathrm{m}$ Pd thicknesses. Figure 4(b) shows the failure mode resulting by wire pull testing. The Ni-P D films with a $0.05 \mu \mathrm{m}$ Pd thickness, shows the low variations and main failure mode was $\mathrm{B}_{\mathrm{C}}$ than the other three $\mathrm{Ni}-\mathrm{P}$ films with $0.05 \mu \mathrm{m}$ Pd thicknesses. The Ni-P A films with $0.05 \mu \mathrm{m}$ Pd thicknesses, shows the failure mode of $\mathrm{B}_{\mathrm{E}}$. $\mathrm{B}_{\mathrm{E}}$ mode suggests that the surface condition of $\mathrm{Au}$ film is not good. From these results, the Ni-P D film was superior to other three Ni-P films in wire bonding properties.

Figure 5 shows the AES depth profiles before heat treatment of the Ni-P A sample with (a) $0.05 \mu \mathrm{m}$ and (b) $0.2 \mu \mathrm{m}$ thickness Pd films, respectively. For both Pd thicknesses, the boundaries between the Au and Pd films were clearly observed and no diffusion of $\mathrm{Pd}$ to the $\mathrm{Au}$ surface was observed.

Figure 6 shows the AES depth profiles, after heat treatment, of the Ni-P A sample with (a) $0.05 \mu \mathrm{m}$ and (b) $0.2 \mu \mathrm{m}$ thickness Pd films, respectively. For both cases, it can be seen that the Pd diffused into the Au films, with 4.5 at. $\%$ and 2.7 at. $\%$ Pd on the surface of Au film for the $0.05 \mu \mathrm{m}$ and $0.2 \mu \mathrm{m}$ Pd films, respectively. No nickel was detected on the Au surface in these samples. In this way, addition of the Pd films as the interlayer was proved to suppress the Ni diffusion into the Au.

\subsection{Effect of Au thickness on wire bonding strength}

Figures 7 and 8 demonstrate the effect of Au thickness on wire bonding strength, before heat treatment and after heat treatment, respectively. Immersion gold plating was applied to produce a $0.05 \mu \mathrm{m} \mathrm{Au}$ film on all samples. In addition, electroless gold films were plated to produce the $0.1 \mu \mathrm{m}$, and $0.2 \mu \mathrm{m}$ samples. All samples had a $0.05 \mu \mathrm{m}$ $\mathrm{Pd}$ film under the Au.

Figure 7 shows the results of wire bonding strength before heat treatment. As also shown in Fig. 3, before the heat treatment, all Ni-P films with different Au thicknesses showed wire bonding strengths above $5.5 \mathrm{gf}$.

Figure 8 shows the results after heat treatment at $200^{\circ} \mathrm{C}$ for 1 hour as the same manner of Fig. 7. Nine conditions showed the wire bonding strength ranging from $5.5 \mathrm{gf}$ to $6.0 \mathrm{gf}$. Only three conditions showed the wire bonding strength lower than 5.5 gf same as in Fig. 4. The 
three lowest values obtained were from samples with $0.05 \mu \mathrm{m} \mathrm{Au}$ thickness. Only Ni-P film D with $0.05 \mu \mathrm{m}$ $\mathrm{Au}$, showed a wire bonding strength value higher than 5.5 gf. However, for all Ni-P films, the variations of wire bonding strengths for $0.05 \mu \mathrm{m}$ Au thickness were higher than those for thicker $\mathrm{Au}$ films. Ni-P A films with a

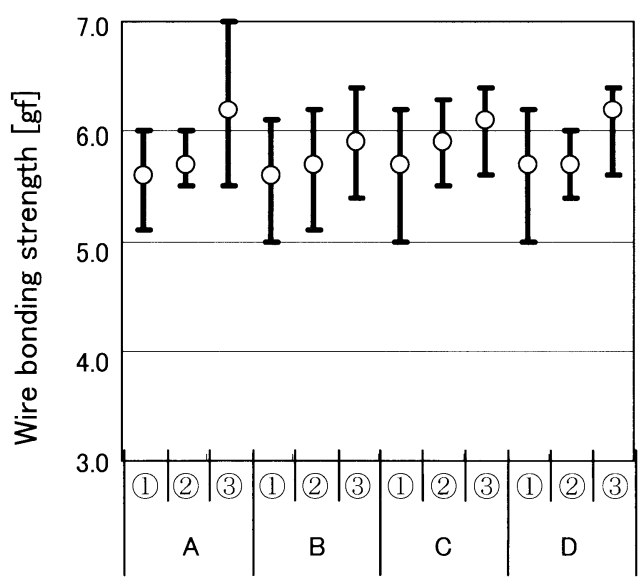

Au thickness (1) $0.05 \mu \mathrm{m}$, (2) $0.1 \mu \mathrm{m}$, (3) $0.2 \mu \mathrm{m}$

Fig. 7. Effect of gold thickness on wire bonding strength for the $\mathrm{Au} / \mathrm{Pd} / \mathrm{Ni}-\mathrm{P}$ system, before heat treatment. Pd thickness is $0.05 \mu \mathrm{m}$ to all samples.

(a)

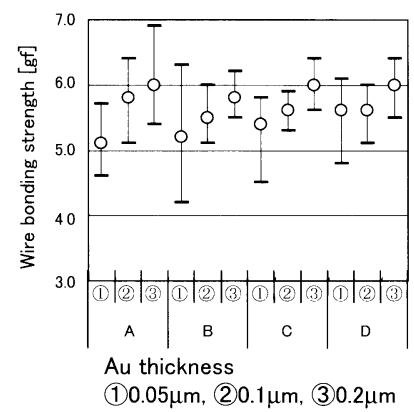

$0.05 \mu \mathrm{m} \mathrm{Au}$ thickness, showed a lower wire bonding strength than the other three Ni-P films with $0.05 \mu \mathrm{m} \mathrm{Au}$ thicknesses. Figure 8(b) shows the failure mode resulting from the wire pull testing. The Ni-P D films with a $0.05 \mu \mathrm{m} \mathrm{Au}$ thickness, shows the low variations and larger $\mathrm{B}_{\mathrm{C}}$ percentage than the other three $\mathrm{Ni}-\mathrm{P}$ films with $0.05 \mu \mathrm{m} \mathrm{Au}$ thicknesses. The Ni-P A films with $0.05 \mu \mathrm{m}$ $\mathrm{Au}$ thicknesses shows the worst result because failure mode $B_{E}$ occurred. $B_{E}$ mode suggests that the surface condition of $\mathrm{Au}$ film is not good. From these results, the $\mathrm{Ni}-\mathrm{P}$ D film is superior to other three Ni-P films from the viewpoint of wire bonding properties.

In Figs. 4 and 8, where $0.05 \mu \mathrm{m}$ Pd films and $0.05 \mu \mathrm{m}$ $\mathrm{Au}$ were coated, the Ni-P films $\mathrm{C}$ and $\mathrm{D}$ of layered structure showed the higher wire bonding strength than the $\mathrm{Ni}-\mathrm{P}$ films A and B of columnar structure. This tendency is similar in failure mode. Generally influence of $\mathrm{Ni}-\mathrm{P}$ films discussed about $\mathrm{P}$ contents. However, these results suggested that $\mathrm{Ni}-\mathrm{P}$ structure is more important than the $\mathrm{P}$ content.

Figure 9 shows AES depth profiles before heat treatment of Ni-P A with (a) $0.05 \mu \mathrm{m}$ and (b) $0.2 \mu$ m thickness $\mathrm{Au}$ films, respectively. For the thinner Au film $(0.05 \mu \mathrm{m}$, shown in Fig. 9(a), Pd was diffused into the Au films and

(b)

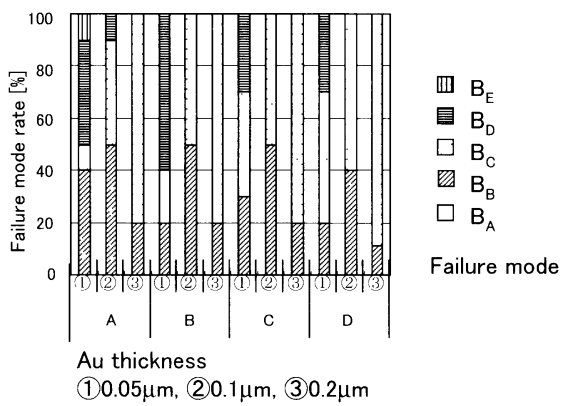

Fig. 8. Effect of gold thickness on wire bonding properties for $\mathrm{Au} / \mathrm{Pd} / \mathrm{Ni}-\mathrm{P}$ system, after heat treatment: (a) wire bonding strength, and (b) failure mode. Pd thickness is $0.05 \mu \mathrm{m}$ to all samples.

(a)

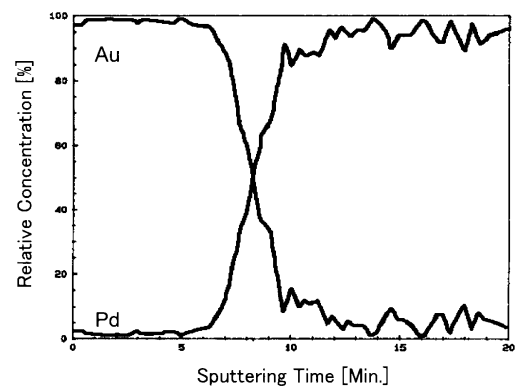

(b)

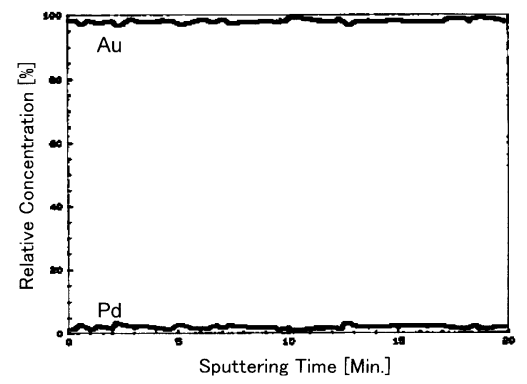

Fig. 9. AES measurements of Au/Pd/Ni-P system, before heat treatment. The Ni-P A samples with (a) $0.05 \mu \mathrm{m}$ and (b) $0.2 \mu \mathrm{m}$ thickness Au films are samples A1 and A3, as shown in Fig. 7. 
(a)

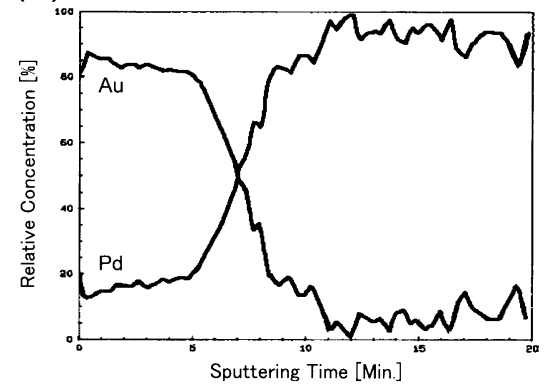

(b)

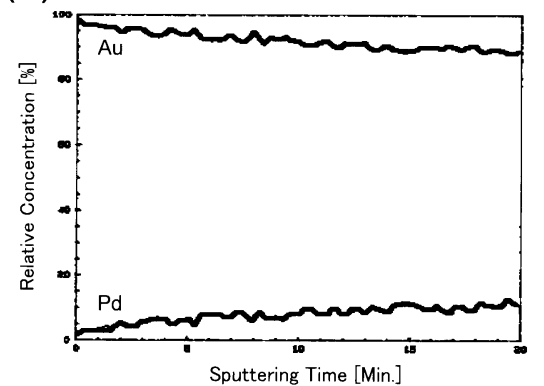

Fig. 10. AES measurements of $\mathrm{Au} / \mathrm{Pd} / \mathrm{Ni}-\mathrm{P}$ system, after heat treatment. The Ni-P A sample with (a) $0.05 \mu \mathrm{m}$ and (b) $0.2 \mu \mathrm{m}$ thickness Au films are samples A1 and A3, as shown in Fig. 8.

Pd was detected on the surface of the Au films. On the other hand, for the thicker Au film $(0.2 \mu \mathrm{m}$, shown in Fig. 9(b)), no Pd was diffused into the Au films and no Pd was detected on the surface of the Au films.

Figure 10 shows the AES depth profiles, after heat treatment, of the Ni-P A with (a) $0.05 \mu \mathrm{m}$ and (b) $0.2 \mu \mathrm{m}$ thickness Au films, respectively. The Pd thickness was $0.05 \mu \mathrm{m}$ for both cases. For the thinner Au film, $0.05 \mu \mathrm{m}$, $\mathrm{Pd}$ diffused into the Au film and 4.5 at.\% of Pd was detected on the Au surface. On the other hand, no Pd was detected on the surface of the thicker Au film $(0.2 \mu \mathrm{m})$. When Fig. 10(b) was compared with Fig. 9(b), it can be seen that small amount of Pd diffused into Au film. However, the amount of the diffused Pd gradually increased with increasing ion sputtering time. Therefore, the Pd also diffused into the thicker Au film; the amount of diffused Pd gradually increased with the increasing depth of the Au film. The thicker Au film $(0.2 \mu \mathrm{m})$, suppressed the Pd diffusion into the Au surface. Again no nickel was detected on the Au surface in this study. The addition of the Pd film as the interlayer again suppressed Ni diffusion.

\section{Conclusion}

Effects of Ni-P substrate structure and $\mathrm{Pd} / \mathrm{Au}$ film thicknesses on the wire bonding strength of electroless $\mathrm{Au} / \mathrm{Pd} / \mathrm{Ni}-\mathrm{P}$ films has been investigated and the following conclusions were obtained:

(1) The Pd interlayer suppressed the Ni diffusion into Au films.

(2) Pd from the interlayer diffused into the Au films during heat treatment.

(3) For thin $\operatorname{Pd}(0.05 \mu \mathrm{m})$ films with thin $\mathrm{Au}$ $(0.05 \mu \mathrm{m})$, the structure of the $\mathrm{Ni}-\mathrm{P}$ substrate was important to obtain the strong wire bonding strength. A layered structure showed the advan- tage of higher wire bonding strength. The influence of the bonding strength was not too much when the film thicknesses of $\mathrm{Pd}$ and Au were over $0.1 \mu \mathrm{m}$.

(4) A thicker Au film prevented the Pd diffusion to the surface of the $\mathrm{Au}$. To reduce the cost, thinner $\mathrm{Au}$ with thinner $\mathrm{Pd}$ is required. Therefore controlling the structure of the Ni-P substrate is one of the most important factors.

\section{Acknowledgements}

This work was supported by a "High-Tech Research Center" project grant for Private Universities; a matching fund subsidy from MEXT (Ministry of Education, Culture, Sports, Science and Technology), 2005-2010.

\section{References}

[1] H. Haji, "Analysis Cases of the Wire-Bonded Interfaces", Journal of the Surface Finishing Society of Japan, 49, 166-171 (1998).

[2] T. Sugizaki, K. Tajima, T. Sasaki, Y. Fukuda, T. Kimura, "Effect of Electroless Nickel/Immersion Gold Finishing on BGA Solder Joints", Journal of Japan Institute of Electronics Packaging, 4, 124-127 (2001).

[3] Y. Watanabe, "Electroless Nickel/Immersion Gold to Enhance the Reliability of the Solder Joint Strength", Journal of the Surface Finishing Society of Japan, 52, 379-381 (2001).

[4] T. Yamamoto, H. Watanabe, K. Izawa, H. Honma, "Effect of Electroless Nickel/Displacement Gold Plating Process on Strength of Solder Joint", Journal of Japan Institute of Electronics Packaging, 6, 339-344 (2003).

[5] H. Nawafune, "The Present and Future Trends in the Electroless Palladium Plating”, Journal of the Sur- 
face Finishing Society of Japan, 42, 1093-1099 (1991).

[6] H. Watanabe, "Electroless Palladium Plating for Electronics Component”, Journal of the Surface Finishing Society of Japan, 55, 651-654 (2004).

[7] Y. Saito, H. Terashima, T. Muramatsu, H. Watanabe, I. Koiwa, H. Honma, "Effect of under Layer Ni-P Film on the Wire Bonding Properties of Electroless $\mathrm{Au} / \mathrm{Pd} / \mathrm{Ni}-\mathrm{P}$ Films", Proceedings of the 16th Micro- electronics Symposium 2006, 235-238 (2006).

[8] H. Watanabe, "Electroless Gold Plating Process for Fine Pattern", Journal of the Surface Finishing Society of Japan, 58, 92-96 (2007).

[9] K. Hasegawa, A Takahashi, T. Noudou, A. Nakaso, "Electroless Ni/Pd/Au Plating for Semiconductor Package Substrate", Journal of the Surface Finishing Society of Japan, 57, 616-621 (2006). 